\title{
ОРГАНИЗАЦИОННО-ПРАВОВЫЕ ФОРМЫ И ПОЛНОМОЧИЯ ДОРОЖНЫХ СОВЕТОВ В ЗАРУБЕЖНЫХ СТРАНАХ
}

\begin{abstract}
Аннотация: В статье приведена сложившаяся практика подключения дорожных советов к управлению дорожным хозяйством. Анализируются состав, функиии и правовая база дорожных советов зарубежных стран. Произведена систематизация дорожных советов зарубежных стран, сопоставлены их функциональные отличия и организационные характеристики. Сделан вывод о возможности использования положительной практики зарубежных стран в Российской Федерации.
\end{abstract}

Ключевые слова: Юриспрудениия, дороги, советь, контроль, пользователи, управление, консультативные, функииональные, программы, эффективность

$\Pi$ роблема повышения эффективности административно-правового регулирования автодорожного хозяйства является актуальной для большинства стран мира ${ }^{1}$.

Одно из наиболее перспективных направлений ее решения видится в законодательном обеспечении подключения к процессу управления дорожным хозяйством пользователей автомобильных дорог. Граждане государства, наиболее заинтересованные в улучшении сети автодорог и законодательно наделенные реальными полномочиями будут способствовать решению тех задач, которые не решаются органами государственной власти, функционирующими в стране на сегодняшний день.

Непосредственное подключение пользователей дорог к процессу управления в большинстве случаев осуществляется через организации, объединяющие широкие круги автомобилистов. В большинстве стран обычно существует по несколько таких организация, включая:

- национальные: торговую палату, ассоциации производителей сельско-хозяйственной продукции, инженерные общества и т.д.;

- национальные организации пользователей дорог: союзы транспортников, дорожные ассоциации, ассоциации грузовых перевозчиков, владельцев и пользователей автобусов и т.д.;

- местные транспортные объединения, объединения отдельных населенных пунктов и т.д.

Представляя основную массу уже объединенных пользователей дорог, такие организации являются важной составляющей частью правовых реформ в области управления и финансирования дорожного хозяйства и Правительства большинства стран обеспечивают

${ }^{1}$ Management and finance of roads. Technical Paper 275. Washington D.C. : World bank. их поддержку и развитие. Участие представителей организаций, представляющих интересы пользователей дорог и обычно входящих в дорожные советы, законодательством многих стран наделены полномочиями по принятию решений в вопросах развития и совершенствования автодорожных сетей.

Создание дорожных советов и их введение в структуру управления осуществляется в первую очередь с целью привлечения пользователей автомобильных дорог к процессу управления дорожным хозяйством. Анализ имеющейся административно-правовой практики показывает, что такой подход в значительной степени способствует повышению качества и эффективности решения проблем управления и адекватного финансирования эксплуатации автодорожной сети, постоянно возникающих перед органами управления дорожным хозяйством. Проведенные исследования законодательной базы зарубежных стран ${ }^{2}$ позволяют сделать вывод о том, что пользователи дорог привлекаются в дорожные советы как в качестве консультантов, способствующих более оперативному и профессиональному принятию управленческих решений, так и в качестве функциональных руководителей и даже руководителей части автодорожных сетей.

Функции, которыми действующие правовые акты наделяют дорожные советы в зарубежных странах, различны и зависят от многих факторов. Выполненные исследования позволяют произвести классификацию функций советов по различным принципам:

- по целям для достижения которых они создаются.

- $\quad$ по принципам законодательного регулирования;

- по структуре, количественному и профессиональному составу;

- по степени наделенности полномочиями.

\footnotetext{
${ }^{2}$ И.Г. Хеггие, П.Вискерс. Управление и финансирование дорог в рыночных условиях. - Вашингтон., В.Б., 1999г. - 109с.
} 
При осуществлении анализа действующих направлений административно-правового регулирования, подобная систематизация позволяет учесть правовые и организационные особенности функционирования дорожных советов.

Первым и основным из рассмотренных правовых принципов систематизации дорожных советов зарубежных стран, является принцип разделения по целям, для достижения которых создаются дорожные советы. В рамках рассматриваемого принципа правовые акты могут определить один из трёх возможных варианта дорожных советов - консультативные, функциональные и смешанные.

К первому виду относятся советы, создаваемые для обеспечения информационной и научной поддержки руководства отрасли, в некоторых случаях для осуществления контроля за целевым использованием средств выделяемых дорожному хозяйству.

Деятельность таких (консультативных) советов направлена в первую очередь на осуществление аналитической деятельности, связанной с планированием различного рода дорожных работ, на разрешение всевозможных проблем, предоставление необходимой информации министерствам транспорта и т.д. Необходимо отметить, что законодательством некоторых стран на консультативные советы возложено осуществление надзорной деятельности за использованием средств, выделяемых на нужды отрасли и не допущение нецелевого использования финансов. Реальной власти консультативные советы не имеют и создаются в первую очередь для повышения эффективности принятия решений по наиболее важным для дорожной отрасли вопросам. Анализ правовой практики ${ }^{3}$ показывает, что такие советы широко распространены и занимают достаточно важное место в дорожном хозяйстве многих зарубежных стран, являясь достойным компромиссом органов государственной власти с пользователями, т.к. с одной стороны позволяют пользователям участвовать в управлении дорожным хозяйством и контролировать распределение и использование налоговых средств, а с другой - позволяют органам исполнительной власти оставаться носителями основных властных полномочий.

Такие советы функционируют в:

- Великобритании (представляют министру информацию по вопросам стратегических направлений дорожной деятельности);

- Германии (консультируют министра по вопросам совершенствования сети дорог) ${ }^{4}$;

${ }^{3}$ И.Г. Хеггие, П.Вискерс. Управление и финансирование дорог в рыночных условиях. - Вашингтон., В.Б., 1999г. - 109с.

4 "Amter und Organisationen der Bundesrepublik Deutschland", Morsbach: BMW, №29, 1991.
- Индии (осуществляют консультации министра по всем вопросам, связанным с управлением национальной дорожной сетью).

Ко второму виду относятся функциональные дорожные советы, создаваемые не только для разрешения проблем, встающих перед, дорожным хозяйством, но и для реального управления вверенными им направлениями деятельности отрасли. В таких случаях законодательством предусмотрено ,что распоряжения и решения дорожных советов, являющихся реальными органами управления, являются обязательными и обеспечиваются санкциями.

Такие советы функционируют в:

- Финляндии (принимают решения по финансированию дорожных программ, проведению научно-исследовательских работ, принимают решения о целях и задачах функционирования дорожной администрации, по административным и многим другим вопросам, необходимым для успешного функционирования дорожного хозяйства);

- Австрии (занимаются вопросами управления автомагистралями) и ряде других стран.

К третьему виду относятся смешанные советы, создаваемые для решения комплекса вопросов как консультационного, так и функционального плана. Такие смешанные советы создаются на основе законов своих стран и действуют в :

- Новой Зеландии (предоставляет министру транспорта необходимую информацию, местным органам - рекомендации по реализации дорожных программ, а также управляет безопасностью движения, эксплуатацией автомагистралей, производит платежи из дорожных фондов и т.д.);

- Японии (изучает состояние дорог, готовит предложения для министра, изучает безопасность дорожного движения, загруженность дорог трафиком, дорожную экологию и готовит предложения министру, а также управляет дорожным фондом).

С точки зрения административно-правового регулирования, деятельность дорожных советов в зарубежных странах обеспечивается тремя различными способами.

Первый из них подразумевает собой правовое обеспечение функционирования дорожных советов в рамках существующего законодательства. Данный способ регулирования деятельности дорожных советов широко распространен в Великобритании и странах англо-саксонской правовой системы. Функции советов определяются непосредственно в законодательном акте и в зависимости от вида совета делятся на консультативные, управленческие и смешанные. В первую очередь функции совета зависят от общей дорожной политики страны, а также от сложившейся 


\section{Право и политика 3 (159) • 2013}

законодательной практики, что существенно влияет на конкретные полномочия дорожных советов, как органов представляющих интересы пользователей дорог.

Советы, создаваемые вторым способом, организуются на основе специально издаваемых указов и распоряжений высших органов исполнительной власти и так же могу иметь как конкретно совещательный, так и исполнительный характер, что четко определяется правовым актом. Так, созданный на основе парламентского указа дорожный совет Финляндии является советом, выполняющим управленческие функции и реализующим переданные ему Финской дорожной администрацией (ФинДА) полномочия по управлению дорогами общего пользования. В ряде стран функционируют советы, созданные на основе президентских указов, являющиеся, как правило, исполнительными советами, руководящими деятельностью дорожных фондов.

К созданным третьим способом, относятся советы, функционирующие на базе специально принятых законодательных актов. К этой категории относятся большинство советов, существующих в современных условиях, поскольку советы этого типа обладают исполнительной властью и действуют в рамках установленных в законе полномочий, что существенно повышает эффективность деятельности отрасли в целом. Эффективность таких дорожных советов обусловлена прежде всего тем, что они самостоятельно разрешают встающие вопросы, анализируя проблему и составляя программу мероприятий по ее разрешению, самостоятельно принимают решения о выделении средств на реализацию запланированных мероприятий, самостоятельно контролируют использование выделяемых средств, исполнение своих решений и т.д.

Необходимо отметить, что советы, функционирующие на базе нового, специального законодательства, является наилучшим вариантом решения проблемы, однако из-за сложностей их принятия, обусловленных необходимостью прохождения законодательно закрепленных правовых процедур, вступление в силу таких законов существенно замедляется. Таким образом, можно сделать вывод о том, что дорожные советы могут с различной степенью успеха функционировать как на основании уже существующего законодательства, так и на основании специально принимаемых законов, указов и распоряжений высших органов государственной исполнительной власти.

С точки зрения организационно-правового регулирования в современных условиях основными являются три аспекта, оказывающих наибольшее влияние на функционирование советов. Такими аспектами являются:
- общая структура совета;

- $\quad$ процедура назначения членов совета;

- профессиональный состав совета.

Исследования правовых актов, определяющих структуру дорожных советов показали, что они, в зависимости от поставленных перед ними задач, достаточно различны.

В Японии предусмотрено включение в состав дорожного совета входят председатель совета, секретарь и три комитета:

- по дорожной политике;

- по регулированию функционирования платных дорог;

- по иным вопросам.

В Финляндии определено, что Совет состоит из председателя, секретаря и членов совета, без деления на комитеты.

В Великобритании законодательство Совет также состоит из председателя, секретаря и не имеет комитетов.

В большинстве случаев, действующие правовые акты предоставляют советам возможность создания и ликвидации комитетов, привлечения для решения наиболее сложных задач необходимых специалистов.

Одним из важнейших правовых вопросов является вопрос определения оптимального профессионального состава совета. В законодательстве различных зарубежных стран ${ }^{5}$ к данному вопросу существуют различные подходы, приносящие, как правило, неоднозначные результаты.

Советы, в состав которых входят политики и малое количество членов от пользователей дорог, проблем в регулировании отношений между советами и органами государственной власти не возникает. Обычно, принимаемые такими Советом решения чаще всего носят текущий административный характер и не затрагивают решения острых вопросов, имеющихся дорожных проблем и выработки общей политики в дорожной сфере. Наличие подобного рода советов мало меняет сложившуюся в дорожной сфере ситуацию и наталкивает на мысль о том, что эти Советы создаются в качестве формальности.

Примером таких Советов является дорожный совет Швеции, состоящий из трех политиков и трех представителей пользователей, дорожный совет Великобритании, имеющий в своем составе председателя и четырех членов, из которых всего один член представляет неправительственные организации. Естественно, что эффективность работы таких советов и их поддержка пользователями дорог не велики.

${ }^{5}$ И.Г. Хеггие, П.Вискерс. Управление и финансирование дорог в рыночных условиях. - Вашингтон., В.Б., 1999г. - 109с. 
Советы, в состав которых предусмотрено включение представителей от большего количества пользователей дорог - напротив, действуют более эффективно. Данные советы направляют свою деятельность на информирование общественности, формируют определенную политику в дорожной сфере, не боятся критиковать имеющиеся недостатки и вносить предложения, направленные на повышение эффективности функционирования дорожного хозяйства. Такие советы являются достаточно независимыми от государства, и имеют возможность независимо оценивать использование выделяемых на эксплуатацию дорог средств, К рациональными по составу, можно отнести Советы, состоящие из людей, более заинтересованных в эффективном управлении дорогами и прилагающих усилия к их модернизации. В состав подобных советов в зарубежных странах входят как представители правительственных департаментов, непосредственно связанных с органами государственной власти и отвечающих за взаимодействие с ними (таких как министерство финансов, министерство транспорта, министерства общественных работ и т.д.), так и представители неправительственных организаций, пользователей дорог - предпринимательских обществ, фермеров, инженеров, ученых, финансистов, юристов и т.д. правовыми актами многих стран предусмотрено, что в советы должны включаться и представители местного самоуправления. Представители пользователей дорог, т.е. налогоплательщиков, заинтересованных в грамотной разработке планов по использованию предлагаемых ими средств, так и в целевом их использовании. Представители же правительственных организаций, отстаивают интересы организаций, от деятельности которых полностью зависит состояние дорог. Таким образом, советы данного типа является наилучшим вариантом взаимодействия пользователей и представителей органов государственной власти.

К таким эффективно функционирующим советам можно отнести:

- японский, где председателем традиционно является председатель дорожной ассоциации Японии, а членами - представители автомобильной промышленности, предпринимательских обществ, торговых союзов, объединений ученых и органов местного самоуправления;

- финский, где председателем совета является обычно бывший руководитель дорожной администрации, членами же совета являются представители министерства транспорта, конфедерации промышленников, автомобильных перевозчиков, муниципалитетов;

- совет ЮАР, включающий в свой состав трех представителей центрального правительства, трех представителей местных правительств, пять представителей от частного сектора и одного - от ученых;

Анализ успешно работающих советов ${ }^{6}$ позволяет сделать выводы о том, что:

- привлечение в советы пользователей из разных областей деятельности способствуют успешному решению стоящих перед дорожным хозяйством целей;

- советы, состоящие в большей части из представителей гос. служащих в основном не обеспечивают защиты интересов пользователей дорог;

- эффективным является привлечение для работы в Совете представителей инженерных и научных объединений.

Важным правовым моментом является и способ избрания председателя.

С точки зрения правового решения вопроса организации работы дорожных советов, нужно, прежде всего, выделить наличие во многих из них комитетов, занимающися конкретными вопросами планирования деятельности, управления и т.д. К работе данных комитетов привлекаются научные и технические специалисты, занимающиеся непосредственно вопросами разрешения складывающихся проблем.

Выполненный анализ показывает, что численность и профессиональный состав дорожных советов, определяется в правовых актах в зависимости от возлагаемых на них функций.

Там где советы создаются для решения проблем, стоящих перед гражданами, в состав входит большинство представителей пользователей.

Там, где целью создания совета является содействие управлению дорожным хозяйством, большинство состава представляет органы управления различного уровня.

При этом рациональная численность советов изменяется в пределах от 7 до 15 человек, что обеспечивает управляемость и конкретную ответственность членов совета за определенные направления деятельности.

В большинстве стран условия функционирования совета, а также условия при которых министр может вмешиваться в дела совета и допустимые способы подобного вмешательства строго ограничиваются законодательством ${ }^{7}$.

Подводя итоги изложенного в статье материала, следует отметить

- во-первых: организационно-правовые формы и функции зарубежных дорожных советов определя-

${ }^{6}$ И.Г. Хеггие, П.Вискерс. Управление и финансирование дорог в рыночных условиях. - Вашингтон., В.Б., 1999г. - 109с.

${ }^{7}$ Snaith, M.S., Richard Robinson, and U. Danielson. 1997. Road Maintenance Management. Basingstoke: MacMilan. 


\section{Право и политика $3(159) \cdot 2013$}

ются целым рядом факторов, к основным из которых следует отнести:

1. Специфику самой правовой базы, обеспечивающей создание и функционирование дорожных советов. Анализ сложившейся практики показывает, что существуют три способа правового регулирования деятельности дорожных советов:

- первый, основывающийся на существующем законодательстве, с дополнительным правовым актом, определяющим основные функции совета;

- второй базируется на указах и постановлениях органов исполнительной власти о создании советов с конкретизацией функций и порядка их деятельности;

- третий базируется на специально принимаемых законодательных актах, позволяющих советам действовать в рамках установленных в законе полномочий.

2. Цели создания советов, в соответствии с которыми они могут быть:

- функциональными, т.е. наделенными определенными конкретными функциями по управлению отдельными направлениями деятельности дорожного хозяйства;

- консультативными, т.е. решающие задачи консультативной и информационной помощи государственным органам управления дорожным хозяйством;

- смешанными. т.е. решающими как задачи по управлению дорожным хозяйством, так и задачи по консультированию и информационному обеспечению органов гос. управления дорожным хозяйством.

3. Структуру Совета, определяющуюся в соответствии с поставленными перед ним задачами и, в большинстве случаев, включающую в себя секретариат и несколько профильных комитетов.

При этом для работы в комитетах дополнительно могут привлекаться специалисты необходимой квалификации.

4. Квалифицированный состав совета, обычно включающий в себя:

- представителей государственных органов, имеющих отношение к дорожному хозяйству;

- представителей пользователей дорог;

- представителей муниципальных образований;

- представителей научных и проектных организаций.

5. Количественный состав дорожного совета, в зависимости от Поставленных задач, изменяющийся в пределах от 7 до 15 человек.

- во-вторых: основными функциями существующих советов, в зависимости от целей их создания являются:

У консультативных советов:

- предоставление министру информации по его запросу;

- изучение состояния дорог и разработка мер по их улучшению;
- изучение состояния вопросов безопасности дорожного движения, загруженности дорог движением, экономической обстановке, обеспеченности финансированием, правовому обеспечению дорожного хозяйства и разработка предложений по их решению;

- изучение программ среднесрочного и перспективного развития дорожной сети и предоставление предложений по их улучшению;

- контроль за целевым расходованием и эффективным использованием средств дорожных фондов.

У функциональных советов:

- проектирование, строительство и эксплуатация национальной дорожной сети;

- управление дорожными фондами;

- управление платными дорогами;

- разработка годовых программ по эксплуатации и развитию сети дорог;

- контроль за системой государственных автомагистралей;

- определение целей и задач дорожной администрации;

- определение приоритетного перечня дорог, нуждающихся в первоочередном строительстве или ремонте;

- разработка норм проектирования и ремонта дорог;

- разработка мер по охране окружающей среды;

- проведение научных исследований по дорожной тематике;

- подготовка предложений по совершенствованию нормативно-правовой базы дорожного хозяйства;

- принятие решений по вопросам бюджетных предложений, финансирования проектов и долговременным программам развития;

- принятие решений по любым другим вопросам, влияющим на эффективность функционирования дорожного хозяйства.

Смешанные советы могут быть наделены и теми и другими функциями, в зависимости от поставленных перед ними задач.

\section{Библиография:}

1. OECD (Organization for Co-operation Economic and Development) 1994/ Road Maintenance and Rehabilitation: Funding and Allocation Strategies. Paris.

2. Management and finance of roads. Technical Paper 275. Washington D.C. : World bank.

3. И.Г. Хеггие, П.Вискерс. Управление и финансирование дорог в рыночных условиях. - Вашингтон., В.Б., 1999г. - 109c. 
Власть и управление

4. World Bank. 1991a. "FY91 Transport Sector review" Report INU-OR8/ Infrastructure and Urban Development department. Washington D.C.

5. Snaith, M.S., Richard Robinson, and U. Danielson. 1997. Road Maintenance Management. Basingstoke: MacMilan.

6. “Bundesverkerswegeplan 1992” (BVWP)? BMV< 1992.

7. "Zur Deschichte und Problematik des Deutschen Strassen - und Wegensrecht”, Baumeister : №31, 1997

8. "Amter und Organisationen der Bundesrepublik Deutschland”, Morsbach: BMW, №29, 1991.

\section{References (transliteration):}

1. OECD (Organization for Co-operation Economic and Development) 1994/ Road Maintenance and Rehabilitation: Funding and Allocation Strategies. Paris.
2. Management and finance of roads. Technical Paper 275. Washington D.C. : World bank.

3. I.G. Kheggie, P.Viskers. Upravlenie i finansirovanie dorog v rynochnykh usloviyakh. - Vashington., V.B., 1999g. - 109s.

4. World Bank. 1991a. "FY91 Transport Sector review" Report INU-OR8/ Infrastructure and Urban Development department. Washington D.C.

5. Snaith, M.S., Richard Robinson, and U. Danielson. 1997. Road Maintenance Management. Basingstoke: MacMilan.

6. "Bundesverkerswegeplan 1992" (BVWP)? BMV< 1992.

7. "Zur Deschichte und Problematik des Deutschen Strassen - und Wegensrecht”, Baumeister : №31, 1997

8. "Amter und Organisationen der Bundesrepublik Deutschland”, Morsbach: BMW, №29, 1991. 